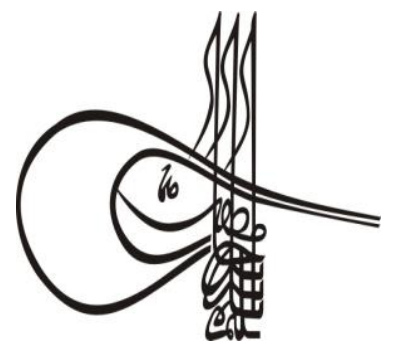

\begin{abstract}
(n)
\end{abstract}
Received/Geliş: 05.03.2019

Gor Report Dates/Rapor Tarihleri:

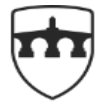

INTERNATIONAL BALKAN UNIVERSITY

EXCELLENCE FOR THE FUTURE IBU.EDU.MK

Research Article / Araştırma Makalesi

Article Info/Makale Bilgisi

$\checkmark$ Accepted/Kabul: 10.06.2019

This article was checked by iThenticate.

\title{
İSLAMİ GELENEKTE TILSIMLI YEDİ SEMBOLLÜ MÜHÜRLER
}

\author{
Azize UYGUN*
}

\begin{abstract}
ÖZET
Semboller nesnelere işaret etmekle birlikte çoğu zaman onlara doğrudan açıklanamayan yönü ile birden çok anlam ve kavramı kapsayacak şekilde anlam yüklenmiştir. Bu yönü ile semboller tılsımlaştırılmıştır. Gizli ilimler alanında sayılamayacak kadar çok tılsımlı sembol örnekleri bulunmaktadır. Bu örneklerden biri ve en meşhur olanı da yedi sembolden oluşan mühürler/hatemlerdir. Özellikle de yaygın ismiyle İsm-i Azam mührü olarak bilinen mühürdür. Büyüsel uygulamalarda neredeyse her derde deva olabilecek şekilde özellikleri olduğuna inanılmıştır. Büyünün gücünü artırmak amacıyla ve insanları koruması için oluşturulan tılsımlarda yaygın olarak kullanılmıştır. Mühürlere tılsımlarda kullanılmasının yanı sıra büyü cetvellerinde, vefklerde ve farklı uygulamalarda da yer verilmiştir. Kur'an'da ve hadislerde hakkında gerçek anlamda bir bilgi bulunmadığı halde mühürlere İslami özellik yüklenerek $\mathrm{Hz}$. Ali'ye ve Gazali'ye atfedilmeye çalışılmıştır. Şems'ül-Maarif'in yazarı Ahmed elBuni tarafından İslam kültürüne aktarıldığı muhtemel olan mühürlere hak etmediği yetenekler verilmiş; kültürlere göre süreç içerisinde değişik anlamlar yüklenmiştir. Semboller farklı toplumlarda farklı özlere bürünebilir. Olağanüstü özellikler yüklenen mühürler de haklarındaki temelsiz iddialardan hareketle büyücüler tarafından maddi ve manevi olarak insanları istismar etme aracı olarak kullanılmışlardır.
\end{abstract}

Makalemizde insanların umutlarını bağladıkları büyüsel uygulamalarda kullanılan, tılsımlı olduğu düşünülen sembollerden biri olan yedi sembollü mühürler incelenecek ve İslami kültürdeki yeri, işlevi ve önemi üzerine durulacaktır. 
Anahtar Kelimeler: Mühür, Hatem, Sembol, T11sım, Büyü

\title{
SEALS WITH TALISMANIC SEVEN SYMBOLS IN THE ISLAMIC TRADITION
}

\begin{abstract}
With symbols point to objects, it is also given meaning to involve multiple meanings and concepts with direct unexplained direction to them. With this aspect, the symbols are charmed. There are numerous examples of talismanic symbols in the field of secret sciences. The most famous and one of these examples is the seals and khatam which are composed of seven symbols. Especially it is a seal known as Ism al-Azam seal. It is believed to have features that are effective in almost all kinds of magical applications. It has been used extensively in amulets created to increase the power of magic and to protect people. Seals were used in talismans as well as in magical rulers and waqf/magical squares in different ways. Although there is no real information about the Qur'an and the hadiths the seals were attributed to $\mathrm{Hz}$. Ali and Al-Ghazali by imposing Islamic features. The seals, which are likely to be transferred to Islamic culture by Shams al-Maarif's author Ahmed al-Buni are given the talents they do not deserve and are given different meanings according to the cultures. Symbols can take different essences in different societies. Considering the fact that the groundless claims about the seals attributed to extraordinary properties they were used as a means of exploiting people materially and spiritually by magicians.
\end{abstract}

In our article, seven symbolic seals will be examined from symbols thought to be talismans used in magical applications where people connect their hopes and the place, function and importance in Islamic culture will be emphasized.

\section{STRUCTURED ABSTRACT}

In the beginning, while the seals were prepared for protection against evil spirits, they were used in later times to search for easy ways to reach what is desired through magical practices. In such applications, it is tried to activate the seal with different methods. Nowadays, the seals placed in khawas and magic books have been copied and written on materials such as paper, leather and linoleum. Its owner move seals as amulets, rings, necklaces, wristbands or are hanged, buried, incinerated or put in water according to the purpose. These symbols which are composed of seven symbols and used in magical applications are called as seals and the name khatam is also used for these symbols in the same frequency. There are various examples of magical seals. The most famous of them among the people are the seals with seven symbols. These are given different names in magical books. Some sources say that these seals were the image of God. It is seen not only in Islamic culture but also in different cultures. 
As expected from the magical formulas, these seals were also expected to have extraordinary powers and were believed to have numerous properties of the seals. Having been loaded with religious and Islamic features these symbols there are those who think that these are the product of revelation. The seven symbols have been assigned letters and it was thought to add power to the power of symbols with the seven letters (ف) , representing each symbol had the same characteristics. It is believed by people that these symbols point to the greatest name of God and are said to represent God's names. In magic books seven symbols were assigned seven the days, seven the kings of demons, seven the angels, seven the planets, and sometimes colours and mines and magical cadwals were prepared. These symbols are also used in wafq and talismans and these are believed to have protective and magical properties.

However, these symbols were seen as talismans prepared to contact the demons. It is believed that each symbol has spiritual beings and is used for communication with angels and demons. It was also believed that the seals were important for the demons and that they were mysterious signs used in contact with spirits. Those who thought that symbols alone will not work in magical practices have abuse jinn and angels and spiritual beings to be able to install extraordinary power on these symbols. The jinn is said to have ties with the symbols, but no information is given on how the jinn is connected to these symbols. This bond is left to the imagination existing with fear of the customer and is asked to visualize it. However, it is thought that a demon, devil and satan can be put into service with the seals that are believed to have magical powers. In addition, it is believed that an agreement could be made between the wizard and these beings and cadwals and amulets and talismans are prepared to invite evil spirits, demon, the king of seven demons and angels.

The most important feature in magical practices is to present the works in a mysterious state. The more the customer cannot understand the applications, the more effective it can. Because the fearful person is open to all kinds of influences. The seals were so spread that they can be seen in the talismanic Ottoman shirts and Sehzade Cem Sultan and other sultan shirts. There is a ring with Solomon's seal written with a pencil and it is seen on Turkmen money and on the silver necklaces and on the healing bowls belongs to the Seljuk period. Besides the seals made of seven symbols, there are magical applications where each symbol in the seal is used individually. It is believed they have the same power and function as the seven symbols. Another place where we meet with the seal is Ahmed er-Rufai sect. However, they call it the seal of roses and the seven symbols and seal came not from the Rufai sect according to them, but from the Qadriyya sect.

There are a lot of books written in Ottoman, Arabic, Persian and Turkish, which are known as khawas books in Islamic tradition. In most of these books, it is possible to see the seals are used in the magical formulas for different purposes. 
Although the information how was entered into Islamic culture is not known exactly this information can be claimed that was introduced to Muslims in the 13th century by Ahmed al-Buni, author of the book Shamsu'l al-Maarif. Those who see the seals as a product talisman of the Islamic tradition wanted to believe that they were given to the $\mathrm{Hz}$. Ali and that these symbols were revealed by Allah as a revelation. Shiite and Sunni groups which have endeavoured the source of the seal to base it on $\mathrm{Hz}$. Ali sanctified it and became effective in the widespread use of the seal. Nowadays, because of the attribution of this seal to $\mathrm{Hz}$. Ali was brought forward by Shia.

It was clearly seen that these symbols used in magical applications had changed from the given examples to the present day. The formulas created by these seven symbols is changed should not affect on people to the magic principle. Because this is a prescription. If they change, the formulas are broken and do not work. Magical formulas are not formula worked in any case and that is appropriate to the logic of the encryption system. Because these formulas must be worked in one way or for one when appropriate conditions are met. However, although encrypting operations are normally put in place to limit the situation, these talismanic symbols in khawas books have been used for unlimited works These are used as the tools of abuse by imposing unimaginable features on them.

Keywords: Seal, Khatam, Symbol, Talisman, Magic

\section{Gíriș}

İnsanların sembollerle ilişkisi düşüncenin var olduğu günden beri devam etmekte ve düşüncenin oluşmasında sembolik anlatımların önemli bir yeri bulunmaktadır. Tarih öncesi dönemlerden bu yana sembollerin şekli, içeriği değişse de olayları, nesneleri sembolleştirme eğilimi değişmemiştir. İnsanoğlu ilk olarak paleolitik çağda av için yapılan büyüyü (Evecen \& Beydiz: 2018, 309); aynı şekilde kutsalı, korkularını, gücü ve din gibi kolaylıkla tanımlanmayan olguları sembolleştirme yoluna gitmiş ve sembolik anlatımlarda geçmişten günümüze birçok sembol bu yolla taşına gelmiştir. Sembolleştirme küçük bir alana birçok şeyi sıkıştırabilme düşüncesidir.

Günümüzde geleneksel bir uygulama olarak insanlar arasında varlığını hala devam ettirmekte olan büyü uygulamalarında semboller sıklıkla kullanılmaktadır. Semboller büyüsel bir formülün içinde, bir vefkle birlikte, tılsım olarak, bir cedvelin satırlarında veya bir koruyucu olarak birçok nesnenin üzerine çizilmiş halde ya da insanların üzerlerinde taşımaları, suya konulup içilmeleri için özellikle de kağıtlar üzerine yazılarak çok farklı amaçlarda kullanılmışlardır. Büyü formüllerinde sayılamayacak kadar çok sembol bulunmasına rağmen bazı semboller insanlar arasında meşhur olmuş ve belli bir ün kazanmıştır. Bu semboller arasında yaygın olanı yedi sembolün bir araya getirilmesiyle oluşturulan ve kendisine farklı isimler verilen yedi sembollü mühürler/hatemlerdir.

Dini unsurlardan beslenen büyüde bu sembollere kasten dinsel bir özellik yüklenilmeye ve dinsel istismar aracılığıyla var olduğu düşünülen gücünün kullanılmasına çalışılmaktadır. Makalemiz bu yedi sembollerin İslam kültüründeki yeri, önemini ve işlevi açısından konuyu incelemeye çalışacaktır. 


\section{A. Mühür/Hatem Çeşitleri}

Gizli öğreticilik olarak da bilinen Ezoterizm'de birçok sırlı simgeden oluşan büyülü, gizemli sembollere mühür denilmekte (Werner: 2005, 561) ve bu semboller için hatem ismi de aynı sıklıkla kullanılmaktadır. Mührün yaygın olarak kullanılan şekli genellikle yedi sembolden oluşmaktadır. Yedi sembol dizisine ve benzerlerine halk arasında ve havas ilminde (gizli ilimler) "İsm-i Azam Hatemi/Mührü” (el-Hüseynî, Kenzü'l-Havâs: 1332, 94; el-Hüseynî, Kenzu'l Esrar: 2005, 193), "Yedi Mühür" (Örnek: Ankara 1966, 42), "Sihirbazın T1lsımı" (İmâm Gazâlî, el-Afâk: 1999, 277), "Hatem-i Hayriye, Havatim, Azimet, Süleyman Mührü/Hatemi, Süleyman T1lsımı, Yedili Hatem, Yedi Şekil, Yedi Tılsım, Celcelutiye Hatemi” gibi isimler verilmiştir (Mesudu'l-Zelyetenî: (t.y.), 28,166; Diyrûbî, Mucerrebati'l-Diyrûbî: 1123, 67; Diyrûbî, Kitabu Fethu'l-Mülk: H.1187, 62; elTilmisanî'l-Mağribî: H.737, 116,125-126; Halevî: (t.y.), Sayfa Yok; Usulul-Hikme, (t.y), 171-282; el-Hüseynî, Kenzü’l Esrar: 2005, 331). Bazı kaynaklarda bunların “Allah'ın Sureti” (eș-Şeyh Atiye: (t.y). 40; el-Tilmisan̂̂'l-Mağribî: H.737, 115) olduğu bile söylenmiştir. Sadece İslami kültürde değil farkl1 kültürlerde de benzerleri görülen bu mühürler için Yahudi geleneğinde "Süleyman'ın Yedi Mührü" tabiri kullanılır. İslami kültürde halk arasında her ne kadar "Süleyman'ın Mührü" tabiri yaygın olarak kullanılsa da gerçekte bu isim mühürde ilk sırada yer alan yalnızca "Altı Köşeli Yıldızın" ismidir. XIII. ve XVII. yüzyıllara gelindiği zaman bu isimlendirme "Beş Köşeli Yıldız" için de kullanılmaya başlamıştır (Scholem: y.y, 687; Smith: 2011, 625).

Toplumsal, kültürel ve dinsel sebeplerden dolayı mühürlerin farklı şekilleri bulunmakla birlikte yaygın olarak kullanılanı yedi sembolden oluşmaktadır. Büyü, fal, astroloji, numeroloji, ebced, tılsımlar ve her derde deva formüllerin yer aldığ havas kitapları genellikle yedi sembolü kullanım amaçlarına göre hayır ve şer mühürleri/hatemleri olarak ayırmışlardır. 7, sembolizmde tamlığın, bütünlüğün, birliğin, göksel uyumun ve tekamülün sembolü olarak kabul edilmiştir (Salt: 2006, 358).

Mührün bazen iyilik için koruyucu olarak, bazen de kötülük için zarar vermek amacıyla kullanıldığı görülür. Çoğu zaman işin amacına göre iyilik yapmada yaygın olan ismiyle hayır hatemi, kötülük işlerinde de şer hatemi kullanılmıştır. Mühürlerdeki sembollerin sayısında ve yerlerindeki sıralamalarda farklılıklar görülebilmektedir. Mühürlerin sağdan sola doğru okunduğu söylenir. Bazı meşhur hayır hatemleri şunlardır: GE

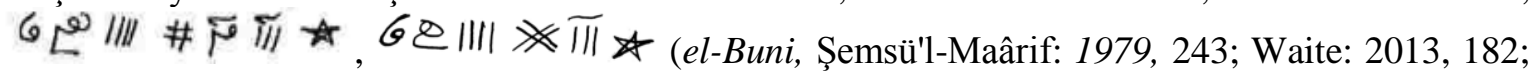
Şeyh Samur Hindî: (t.y.), 65-84; İloğlu: (t.y.), 1799; Kısa, Büyü Notlart: (t.y), 31). Hayır hatemi genellikle düşmanların zararlarından korunmak için kullanılmıştır ve vefk olabilecek şartları taşımamasına rağmen İsmi Azam Vefki olarak da bazı büyüsel uygulamalarda geçmektedir (Çakar: 2005, 462).

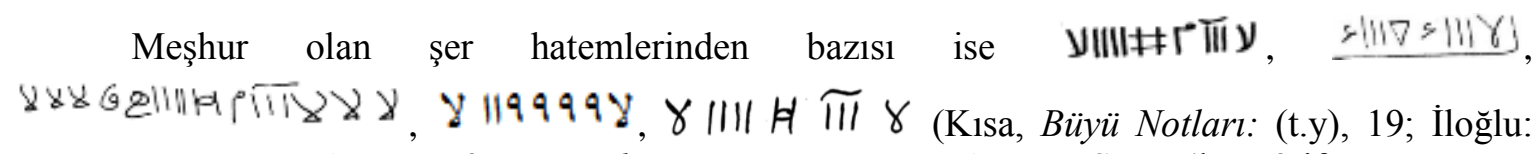
(t.y.), 1064-1123; el-Hüseynî, Kenzü'l-Havâs: 1332, 32; el-Buni, Şemsü'l-Maârif: 1979, 243) şeklindedir. Şer hateminin sembolleri arasında birtakım farklılıklara rağmen genellikle sıralamalarda hayır hateminde ilk sırada yer alan beş köşeli ve altı köşeli yıldızın yerine ${ }^{\prime}$ lamelif'e benzeyen sembolün kullanıldığı görülür. Muhtemelen buradaki sembol, mührün İslam kültürüne geçmesiyle birlikte Arapça lamelif şekline bürünmüş ve şer olanı ifade etmek amacıyla başka bir sembol veya harften değiştirilmiş veya dönüştürülmüştür. 


\section{$20+\infty 1$ 正}

Hayır ve şer hateminin birlikte yer aldığı bir diğer mühür de Notlart: 95-96) şeklindedir. Hilal, haç, gamalı haç veya svastika gibi farklı dinlere ait sembollerin aynı hatemde bulunması bu tür uygulamalarda dinsel kaygının olmamasından ve herhangi bir dinin sembolünün kullanılmasında bir sakınca görülmemesinden kaynaklanmaktadır. Gerçekten de büyüsel uygulamalarda dinsel değerler ve sembollerin dikkate alınmadığı aksine formülün tutması için özellikle dinin emrettiğinin tam tersi uygulamalar yapıldığı sıklıkla görülür.

Tılsımlı yedi sembolün dışında büyü ve havas kitaplarında yer alan farklı mühür çeşitleri de bulunmaktadır. Bunlardan bazıları yedi sembolden oluşmakla birlikte aşağıda görüldüğü gibi daha az ve daha fazla sayıda sembolden oluşan mühürlerdir.

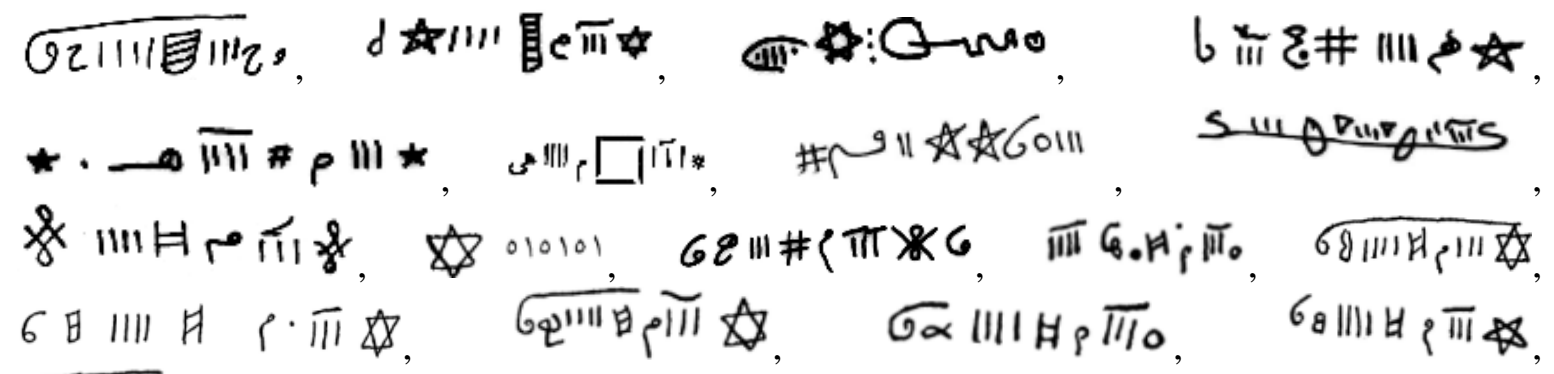

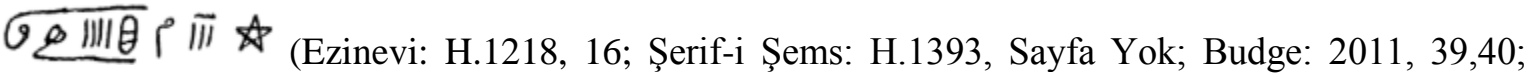
Ahmed: (t.y.), 68,85; el-Tilmisanî'l-Mağribî: H.737, 116-141; el-Hüseynî, Kenzü’l Esrar: İstanbul 2005, 193; er-Radavî: (t.y.), 294; Smith: 2004, 168; Dawkins: 1944, 146).

Çeşitli özellik ve fonksiyonlara sahip mühürler zaman içerisinde değişerek ve çeşitlenerek büyüsel uygulamaların yanı sıra yüzükler, kolyeler, levhalar, kilimler, paralar ve takılar üzerinde de yer almaya başlamıştır (Kuşoğlu: 1998, 26-27, 33).

\section{B. Mühürlerin Harflerle İlişkilendirilmesi}

Yedi sembollere harfler tahsis edilerek sembollerin gücüne güç katıldığı, her bir sembolü

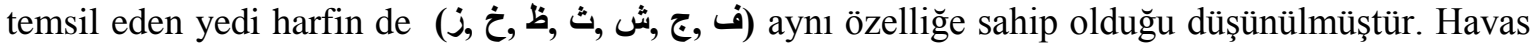
kitaplarına göre bu harflerin Fatiha Suresinde geçmeyen harfler olduğu söylenir. Havas kitaplarında Hurûfu Sufliyei Zulmânîye (Kısa, Havass'in Derinlikleri: 2005, 83) ve Hurufu Muacceme (el-Buni, Şemsü'l-Maârif: 1979,) olarak farklı şekillerde isimlendirilen bu yedi harfin mühürdeki sembolleri temsil ettiği düşünülür. Allah'ın bazı esmalarının baş harfi olduğu da söylenilir. Buna göre harfler sirayla (يكز ريبخ ريهظ تباث روكش رابج درف) (Ferd, Cebbâr, Şekûr, Sâbit, Zâhir, Habîr, Zekî) şeklinde isimlendirilmiştir. Bu harflerin her birinin mühürdeki bir sembolle eşleştirilmesinin sebebine ve niçin o sembolün seçildiğine dair herhangi bir bilgi verilmemiştir. Öyle ki havas türü kitapların dışında bu bilgilere hiçbir yerde rastlanmamaktadır (İmâm Gazâlî, Celcelutiye: 2011, 47; (Mesudu'l-Zelyetenî: (t.y.), 296). Aşağıda sembollerin yerine onları temsil ettiği düşünülen sadece harflerin kullanıldığı bir örnek bulunmaktadır (Halevî: (t.y.), Sayfa Yok). Sembolleri temsil eden harflerle oluşturulan bu tılsımın da sembollerin bulunduğu tılsımlar kadar etkili olduğu düşünülür.

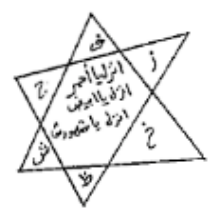

Şekil 1 Sembollerin yerine sadece Hurûfu Sufliyei Zulmânîye harflerinin kullanıldığı bir tılsım. 


\section{Mühürlerin Cinlerle İlişkilendirilmesi}

Mühürlerin cinler için önemine, onlar için yol göstericiliğine, her bir sembolün bir cine karşıllk geldiğine ve ruhlarla irtibatta kullanılan sırlı işaretler olduğuna da inanılmıştır (Mesudu'lZelyetenî: (t.y.), 28). Cinlerle irtibat için yıldızların konumları hesaplanmaya ve sembollerin yazılacağı saatler belirlenmiştir (el-Tuhi: 2003, 133). Tı1sımlı sözlerin tekrarlanmasıyla gücün ortaya çıkacağına ve bu şifrelerin ruhani varlıkları tek tek ya da toplu olarak davet etmede etkili olacağına ve sembolleri gören veya duyan ruhların büyücünün emirlerini yerine getireceklerine inanılmıştır.

Havas kitaplarına göre yıldız şeklindeki sembol \&, üstat لبئاقاقور (Ruk1yail) ve onun yeryüzü hizmetçisi بذدمل (el-Muzhib) içindir. İkinci sembol ise III, üstat لبئاربج (Cebrail) ve onun

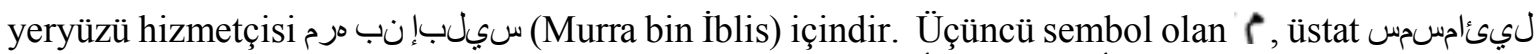
(Semsemail) ve onun yeryüzü hizmetçisi olduğu düşünülen رححم (Ebi Muhraz el-Ahmar)

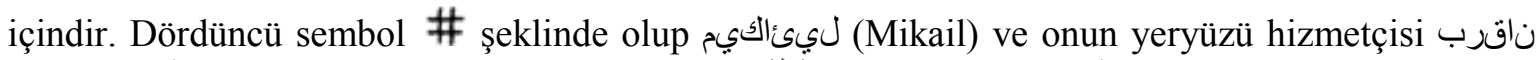

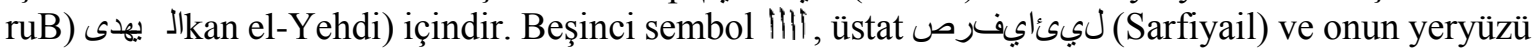

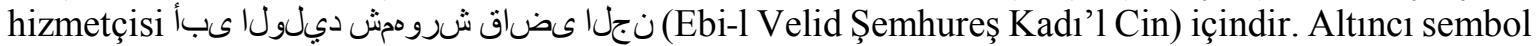

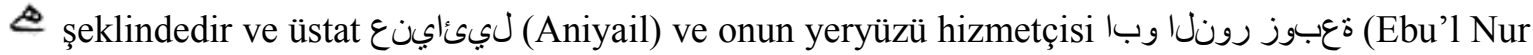
Zübea) içindir. Yedinci sembol ise $G$ şeklinde olup, üstat لنيئايفسك (Kesfiyail) ve onun yeryüzü hizmetçisi ناجل شيج دئاق خون ىبأ نوميم (Meymun Ebi Nuh Kaid Ceyşü'l-Can) içindir. Yedi sembollü hayır hateminin, Hz. Ali'nin kasidesi olduğu iddia edilen Celcelutiyye'de, davet mührü olduğu ve evrendeki bütün ruhani varlıkların bu mühre tabi olduğu da iddia edilir (Mesudu'lZelyetenî: (t.y.), 28). Fakat bu bilgilerin alındığı kitaplar havas kitaplarıdır ve bu bilgilerin kaynağıyla ilgili herhangi bir bilgi verilmemektedir.

Büyülü güçlere sahip olduğu düşünülen mühürlerle bir iblisin, cinin, şeytanın hizmete alınabileceği, büyücü ile bu varlıklar arasında bir anlaşma yapılabileceğine inanılmış (Yıldırım: 2008, 647; Werner: 2005, 561) ve hüddam/cin elde etmek, bir ruhaniyi, yedi cin kralını ve melekleri davet etmek için hatemle oluşturulan cedvel, tılsım ve vefkler (Ertuğrul: (t.y.), 171; Halevî: (t.y.), Sayfa Yok; Usulul-Hikme: (t.y), 176; el-Endelûsî: H.343, 68) hazırlanmıştır. İsrail'deki Süleyman mabedinin duvarına yedi sembolün oyulduğuna ve bu mührün aracıllı̆ıyla oranın yedi cin tarafindan ve tahatil ismi verilen ruh dünyası tarafindan korunmakta olduğuna dair efsaneler de bulunmaktadır (Graham: 2011, 26-27).

\section{Mühürlerin Vefk, Cedvel ve Tılsımlarda Kullanılması}

\section{Cedvel}

Cedvel, İslami gelenekte yazılı büyü türünde yer alan en yaygın şekillerden biridir. Cedveller, plan anlamına gelen ve sihir ve tılsımın yapıldığ 1 amaca göre değişiklik gösteren birtakım sembollerin, isimlerin, harflerin, rakamların yazıldığı kare, dikdörtgen, üçgen ve daire gibi geometrik şekillerden oluşmaktadır. Bunların üzeri enine ve boyuna çizgilerle bölünerek eşit hâneler elde edilir. Hanelerde yer alan çeşitli unsurlar arasında birtakım ilişkiler olduğu düşünülerek art arda dizilmelerinden bazı etkiler elde edilmeye çalışılır. Cedveller hazırlanış sebebine göre daha çok korunma, güç ve şifa bulma amaciyla boyuna, pazuya, omuza veya belden yukarı olmak şartıyla vücudun kısımlarına takıldığı gibi suda eritilerek ilgili kişiye içirilir yahut yakılarak kişi dumanı ile tütsülenir.

Mühürdeki sembollerin haftanın her bir gününe tahsis edilmesiyle hazırlanan bu cedvellere havas geleneğinde Sub'a Havatim ismi verilmiştir (el-Bûnî, "el-Lü'lü vel-Mercân: (t.y), 17; el-Tûhi, Kitâbu Sihru'l-Kehhân: (t.y), 131,167; Şerif-i Şems: H.1393, 57; el-Tilmisanî'l-Mağribî: H.737, 72; 
Halevî: (t.y.), Sayfa Yok). Ayrıca Mühr-ü Süleyman şeklinde ifade edildiğine de rastlanmaktadır. Benzer örnekler Yahudilikte, İbrani dilinde hazırlanmış olarak da görülür.

\begin{tabular}{|c|c|c|c|c|c|c|}
\hline 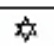 & ? & III & $\neq$ & r & 解 & 6 \\
\hline 9 & 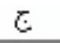 & $\Leftrightarrow$ & $\dot{H}$ & b & $\dot{c}$ & $j$ \\
\hline Fird & istis & souse & serat & Whit & Hotar & t \\
\hline Fast & Fenas & 801 & gerearso & Peworroo & $\mathrm{cm}$ & ancrext \\
\hline$F>31$ & cosis & soressid & Nol & seses: & $\mathrm{ANA}$ & oxses \\
\hline 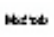 & $\mathrm{HE}$ & Ars: & Burper & fertury & Alece & reaser \\
\hline ans, & ve & $w_{\mathrm{ys}}$ & Nerüt & $d x y$ & wis & sean \\
\hline
\end{tabular}

Şekil 1 Türkçe hazırlanmış bir cedvel örneği.

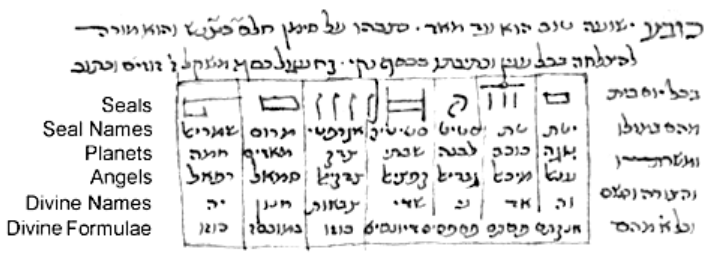

Şekil 2 İbranice hazırlanmış cedvel örneği.

İbranice hazırlanan cedvel en az XVIII. yüzyıla ait olup, ilk kez Kabala tarafindan kullanılmıştır (Graham, A Comparison: (t.y.),18; Kaplan: t.y, 172,173; Redgrove: 1920, 63). Tablolardaki sıralamalarda bazı farklılıklar bulunsa da cedvellerin birbirine benzerlikleri açık bir şekilde görülmektedir. Yedi güne ayrılan her iki tabloda da ilk sırayı yedi mühür almıştır. Yedi gezegen haftanın yedi gününe tahsis edilmiştir. Yedi sembol yine yedi melekle ve yedi cin kralıyla ve Esmaü'l-Hüsna'dan bazı isimlerle de özdeşleştirilir. Gezegenleri sıralama usulü ise Kaldelilerin gezegenleri sıralama şeklidir (Farklı cedvel örnekleri için bkz, Ek: 13, 14, 15, 16).

Oluşturulan cedvellerin büyüsel formüllerin hazırlanmasında ve yerine getirilmesinde yardımcı araçlar olarak kullanılmalarının yanı sıra bazı kitaplarda büyüsel formülün bir parçası olarak yer aldıkları da görülür. Genellikle cedvellerde bulunan mühürdeki semboller her ikisinde de aşağı yukarı aynı sembollerdir. Her sembolün bir harfi, meleği, cini, esması, günü, yıldızı, buhuru, madeni bulunmakta ve cedvellere yeni haneler eklenerek atfedilen unsurların sayıs1 çoğaltılabilmekte veya azaltılabilmektedir. Her güne bir sembolün tahsis edilmesinin Asur, Babil medeniyetlerinin tanrı, astroloji, madenler, sayısal değerler bilgilerinden ve sonrasında da Yahudi büyüsel uygulamalarından faydalanılarak hazırlandığg anlaşılmaktadır.

\section{Vefk}

Sözlükte uyum, uygun, münasip anlamına gelen vefkin şekli genellikle bir karenin eşit bölünmüş kutucuklarına rakamlar koyarak hazırlanır. Hanelerde yer alan sembol, harf ve rakamların birtakım sihrî anlamlar taşıdığına inanılır. Vefklerde usul, sağdan sola, yukarıdan aşağıya veya bir köşeden diğer köşeye kutucuklardaki sayıların toplamının birbirine eşit olması şeklindedir. Fal, kehanet, astroloji, matematik ve astronominin verilerinden yararlanılarak yapıldığı söylenilen bir tılsım türü olan vefkin temelinde harf ve rakamların özel güçlere ve niteliklere sahip olduğu inanc1 yatmaktadır. Muhtemelen Gazâlî gibi büyük bir otoritenin ününü istismar etmek amacıyla ilk cedvel ve vefkler Gazâlî’ye ait olarak gösterilmeye çalışıılmıştır (Aydın: 1993, 214).

Vefk meselesi dinî literatürde Kur'an ve hadislerde yer almamasına ve din âlimlerince reddedilmesine veya onu çağrıştıracak herhangi bir ifade bulunmamasına rağmen halk inanışlarında, İslâm kültüründe yaşatılmıştır. Vefklerin ilk örneklerinin Gazali'den önce Câbir b. Hayyân ve İhvân1 Safầ'da da rastlandığı da söylenmektedir (Çelebi: 2012, 605).

Mühürdeki yedi sembolle hazırlanan vefklerin yanı sıra bu sembollerin biri veya birkaçı kullanılarak hazırlanan vefkler de bulunmaktadır. Vefkler büyülerde daha çok koruyucu bir tılsım görevi üstlenmiştir. Yedi sembolle hazırlanmış bazı vefk örnekleri aşağıda görülmektedir. 


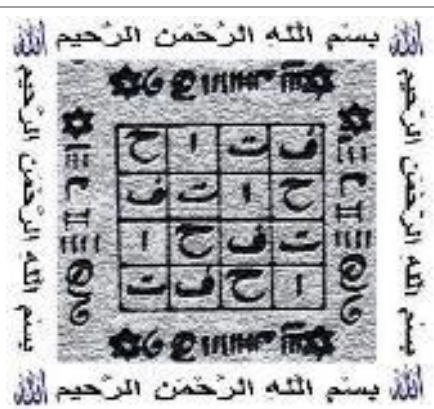

Şekil $3 \mathrm{Bu}$ vefk gümüş yüzük üzerine yazdırılarak büyüsel uygulamalarda kullanılan bir dörtlü vefktir. İsmi Azam vefki olarak da ifade edilir.

Başka bir örnekte ise mührün sonuna da beş köşeli yıldız eklenerek 8x8'li vefk yapılmıştır.

\begin{tabular}{|c|c|c|c|c|c|}
\hline रा6 & हा। & 67 & & & i11 $A$ \\
\hline तो & $\bar{G}$ & En & 1. & A & rlî̃ \\
\hline r III & $\$$ & 61 & & & 4 \\
\hline की 1 & 㣙 & $\$ 6$ & & $=$ & IIIII \\
\hline 5101 की & if & đิโ & & & 5 \\
\hline$e /|111|$ & की & P & & & 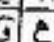 \\
\hline बद & דורו & 神 & & & 46 \\
\hline$\theta 0$ & हा। & |ill| & & & iI \\
\hline
\end{tabular}

Şekil 4 Hüddam/hizmet eden cin elde etmek ve bir ruhaniyi, yedi cin kralı ve melekleri davet etmek için oluşturulmuş bir vefk (Usulul-Hikme: (t.y.), 176).

Yedi sembolün tamamının değil de sadece üç sembolün kullanılarak hazırlandığı 3'lü bir vefk örneği ise şu şekildedir.

\begin{tabular}{|c|c|c|}
\hline $\mathrm{H}$ & $\bar{\pi}$ & $\not$ \\
\hline$\not 8$ & H & $\pi$ \\
\hline$\pi$ & $\frac{k}{\not}$ & $\overline{\mathrm{H}}$ \\
\hline
\end{tabular}

Şekil 5 Yapılan büyü ve sihri tesirsiz hale getirmek için kullanılan bir büyü uygulamasında hastanın üzerinde taşıması için hazırlanmıştır (İloğlu: (t.y.), 1799, 478; Pamuk: (t.y.), 40).

Vefkler farklı nesneler üzerine çizilerek de kullanılmışlardır. Bu örnekte ise mühür şifalı tasın içine yazılmıştır.

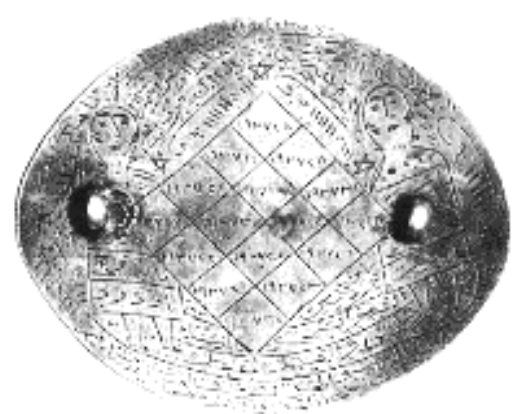

Şekil 6 Hayır hateminin şifalı taslara çizilme örneği (Fodor: (1987-1988), 273).

Vefk ve mührün bir arada kullanıldığı başka bir örnek ise şöyledir: 


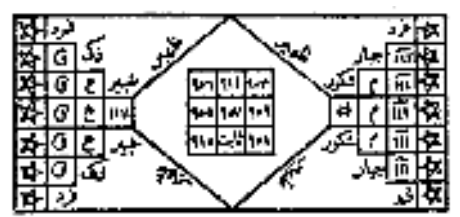

Şekil 7 Hacetlerin yerine getirilmesi için yedi cin kralı ve askerlerine hitabın yar aldığ yedi mühür ve vefkle birlikte hazırlanmış bir büyü örneği (Usulul-Hikme: (t.y.), 182).

Burada verilen vefklerin dışında sayısız benzer vefk örneklerini bulmak mümkündür. (Farklı örnekler için bkz, Ek: 17, 18,19, 20).

\section{Tilsım}

Bir çeşit büyü, muska veya astrolojik bir büyü formülü olan tılsım, kelime olarak Arapça tılsam kelimesinden gelmekle birlikle Yunanca telasma'dan (bir rit) türetilmiş olduğu söylenilir (Gündüz: 1998, 370). T11sımın kazalardan, büyülerden, hastalıklardan koruyucu bir gücünün olduğuna inanılır. Tılsım terim olarak "uygun zaman ve konumdaki aktif semavî kuvvetlerin pasif yer güçleriyle temasa geçerek onları etkilemesi keyfiyeti” diye tanımlanır (Çelebi: 2012, 91).

Yedi sembolle hazırlanmış farklı şekillerde tılsım çeşitleri bulunmaktadır.

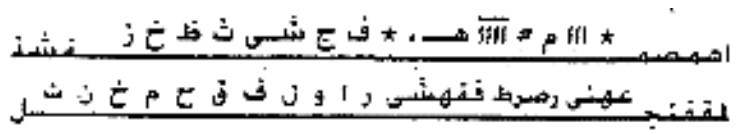

Şekil 8 Kâğıda yazılan bu tılsımın çörek otu, Meryem ağacı, kendir gibi bitkilerle tütsü yapılarak hastanın sihirden kurtulması için kullanılması istenmiştir (Ahmed: (t.y.), 68).
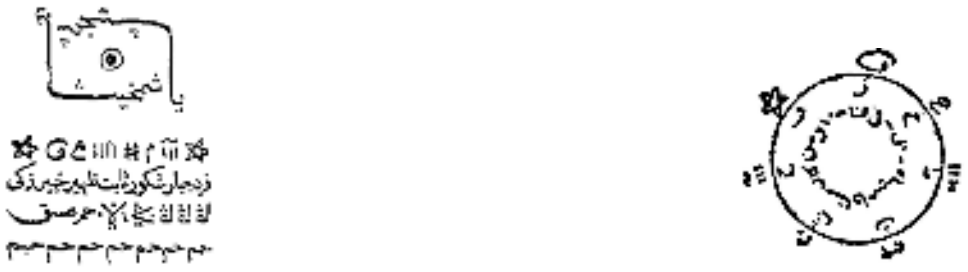

Şekil 9 Düşmana galip gelmek için hazırlanmış bir tılsım Şekil 10 Sevgi için hazırlanmış bir tılsım.

(Usulul-Hikme: (t.y.), 182).

(el-Tilmisanî’l-Mağribî: H.737, 116).

Bunların dışında her sembolün kendi içinde mevcut bir gücü bulunduğuna inanılmakta ve her biri ayrı ayrı yedi mühür gibi kullanılabilmektedir. Așağıdaki örnekte de sadece beș köșeli yıldızın kullanılması, mührün kullanımıyla aynı değerde görülmüştür. Yıldız yedi mühür adedince yedi kez yazılmıştır (Daha fazla tılsım örneği için bkz, Ek: 21, 22, 23, 24).

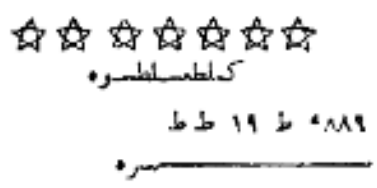

Şekil 11 Beș köșeli yıldız kullanılarak sihrin iptali ve bağlıyı çözmek için hazırlanan bir tılsım. (Usulul-Hikme: (t.y.), 179).

Sembollerin birlikte değil de ayrı ayrı kullanıldığı bazı örnekler ise şöyledir: bir örnekte bu iki sembol $\approx$ birçok hastalıktan şifa bulmak amacıyla kullanılmıştır. IIII Dört adet elifmiş gibi duran bu sembol ise gayri meşru olmayacak şekilde bir kimseyi kendine celb etmek, bağlamak için 
kullanılmıştır. Bu sembol ise $\pi$ bir zalimi kahretmek için, annesinin ismi ile birlikte yazılır. Arapça'daki elif harfine benzemektedir. Elif, İhvan-1 Safa'da Allah'ın birliğine işaret olarak görülmüştür (Bozkurt: 2018, 285). Üç sembolün yer aldığı bir örnekte ise $\pi$ r bu semboller hastalık ve cin musallat etmek için kullanılmıştır (el-Hüseynî, Kenzu'l Esrar: 2005, 194-218).

T11sım üzerine yazılmış olan büyü dili tılsımın gizemli görünmesini sağlar ve bu metinleri çözebilmek neredeyse imkansızdır. T11sımın amacı metinleri şifreleyerek formülü karmaşık bir hale getirmek ve oluşturulan bu gizemle karşıdaki kişide korku veya ürperti uyandırmaktır. Genellikle de tılsımlar bir kişi veya olay için özel olarak hazırlanmışlardır.

\section{E. Mühürlerin Büyüsel Kullanımı}

İslami gelenekte havas kitapları olarak bilinen Arapça, Farsça ve Osmanlı ve günümüz Türkçesiyle yazılmış oldukça fazla kitap bulunmaktadır. Bu kitapların çoğunda yer alan büyüsel formüllerde farklı veya aynı amaçlarla kullanılan mühürleri görmek mümkündür. T11sımlarda mürekkebin rengi, yazma usulleri, tılsımı yazma zamanı gibi hususlar önemlidir ve formüllerin gücünü artıracağına inanılmıştır. Mühürler de benzer amaçla kullanıldıkları için İslami geleneğe ait büyüsel uygulamalarda mühürleri yazmak için genellikle farklı renkler kullanılmıștır. Renkli mürekkeple farklı nesneler üzerine yazılan mühürlerin daha etkili olacağına inanılır. İslami gelenekten farklı olarak Yahudilerde tek renk olarak siyah tercih edilmiştir (Graham, A Comparison: (t.y.),27).

Mühürler ilk zamanlar kötü ruhlara karşı korunma amaciyla (Scholem: 1949, 246), sonraki zamanlarda ise daha çok büyüsel uygulamalarla istenilene ulaşmanın kolay yollarını aramada kullanılmıştır. Çok farklı usullerle mührün aktif hale getirilmesine çalışılır. Günümüzde ise daha çok havas ve büyü kitaplarında yer alan mühürler buralardan kopya edilerek kâğıt, deri, muşamba gibi malzemelere yazılarak muska, yüzük, kolye, bileklik olarak taşınmakta veya amaca göre herhangi bir yere asılmakta, gömülmekte, yakılmakta veya suya konularak içilmektedir.

Büyüsel uygulamalarda mühürlere sayısız özellikler yüklenmiştir. Düşmanlardan, hastalıklardan, şiddetli acı ve üzüntülerden korunma amacıyla üzerinde taşıma, rızık ve bereket sağlama, cinlerden korunma ve davet etme, meleklerin itaatini sağlama, kişiyi kabir azabından kurtarma, bir kale, hisar ve evin harap olmasını sağlama, balmumu üzerine yazılarak yıkılması istenilen yerin eşiğinin altına gömme, define bulma, bir kimsenin yerini değiştirmesini sağlama, hüddamlardan yardım dileme, bir kişiyi yerinden etme veya geri getirme, bir zalimi mahvetme, kişiyi cin ve şeytanın elinden kurtarma, tutuklu bulunan adamı hapishaneden kurtarma (İloğlu: (t.y.), 1799; (el-Tilmisanî'l-Mağribî: H.737, 115; Diyrûbî, Kitabu Fethu'l-Mülk: H.1187, 94-102; İbnu'l-Arabi, el-Kibritu'l-Ahmâr: H.636, 15; Mevlevî: (t.y), 217; el-Buni, Şemsü'l-Maârif: 1979, 238; el-Hüseynî, Kenzü'l-Havâs: 1332, 35-37; İmâm Gazâlî, el-Afâk: 1999, 208,233; Usulul-Hikme, (t.y), 178; Takî'l-Mukaddem: 2001, 480; Halevi: (t.y), Sayfa Yok; el-Endelûsî: H.343, 68), muhabbet ve celbi sağlama, orduları yenme, şu alemde istenilen her şeyi oldurma, bir beldeden bir beldeye uçma, eşkıya ve soygunculardan korunma, bir kimseyi recm ettirme, bir kimsenin uykusunu yok etme, iki kişiyi birbirinden ayırma veya barıştırma (el-Buni, Şemsü'l-Maârif: 1979, 238; el-Hüseynî, Kenzü'lHavâs: 1332, 35-37; Usulul-Hikme: (t.y), 173; Ahmed: (t.y.), 84; el-Tûhi, Kitâbu Sihru'l-Kehhân: (t.y), 15; Mesudu'l-Zelyetenî: (t.y.), 218; Şerif-i Şems: H.1393, Sayfa Yok; el-Tilmisanî’l-Mağribî: H.737, 102; İloğlu: (t.y.), 441) gibi çoğu hedeflere ulaşmada mührün kullanılması tavsiye edilmiştir.

Bunların dışında meşhur havas kitaplarından biri olan, havas ilmiyle ilgili uygulamaları İslam kültürüne taşıdığı düşünülen Şemsü'l-Maarif' in yazarı el-Buni, mühür için, "bunun öyle bir gaye ve maksadı vardır ki sonsuzluğa kadar uzanır" demekte ve mührün sonsuz bir kullanımının olduğunu söylemektedir. Buni’nin kitabına göre bu mührü; ancak tam riyazet halinde bulunanlar,

Turkish Studies - Comparative Religious Studies

Volume 14 Issue 2, 2019 
oruç ve dini ibadetini aksatmayanlar, züht ve takva sahibi olanlar kullanabilir. Mührün batıni ve zahiri iki etkisinin olduğuna inanılır. Zahiri dıştan görünen şeklidir, batıni olan ise Hz. Ali'ye atfedilen manzum olarak yazılmış olan duada yer alır (el-Buni, Şemsü'l-Maârif: 1979, 242-251). Bâtıni gruplara göre, Hz. Peygamber Kuran'ın zahirini tebliğ ederken, Hz. Ali de bâtıni yönünü tebliğ eder. Hz. Ali'ye ayrıcalık tanınarak Kuran'ın inceliklerinin öğretildiği, gizli manalarını bildiği düşünülmektedir. $\mathrm{Bu}$ İsmailiye Batıniliğinin temel görüşlerindendir. Batıni ilim hakkında mutasavvuflar da Kuran'da avam ve alimlerin bilmediği yalnızca arif ve velilerin vakıf olduğuna inandıkları gizli manaların bulunduğuna inanmışlardır (Ünlüsoy: 2011, 95). Hz. Ali’ye birçok kitap, kaside ve şiir nispet edilmiştir.

Mührün tam olarak nasıl ortaya çıktığının bilinmemesinden dolayı halk arasında dolaşan ve havas türü kitaplarda anlatılan birçok rivayetler ortaya çıkmıştır. Bu rivayetlerden bazılarına göre mühür, İstanbul'da Ayasofya Camiinde ve Kabe'nin kapısında yazılmış olarak bulunmaktadır (Graham, A Comparison: (t.y.), 24). Yine bu sembollerin Tevrat, İncil ve Kuran'da yer aldığ da iddialar arasındadır (el-Hüseynî, Kenzu'l Esrar: 2005, 73). Bu iddialara göre IHI ¿ şeklindeki bu üç sembol Tevrat'ta Allah'ın adını gösteren altı harfli mühür olarak geçer. Dikey çizgiler tek tek bir sembol olarak sayılmıştır. Bu iki sembol ise $\Gamma^{\circ} \dagger \vDash$ İncil'de bulunan semboller iken; Kur'an'da bulunduğu iddia edilen sembollerin Tiix bu şekilde iki adet olduğu söylenilir (el-Buni, Şemsü'lMaârif: 1979, 247). Havas kitapları her zamanki gibi bu sembollerin nereden alındığına ve bu bilgilerin kaynağına dair herhangi bir açıklama yapmamaktadır. Bu tür kitapların bazılarında kitabın yazarları daha çok, şeyh olarak saygı duydukları kimselerin sözlerinden hareketle "bu şekilde söylenmiştir," şeklinde ifadeler kullanarak bu bilgileri tam bir itaatle kabul etmişlerdir.

İslami gelenekte genellikle mührün kaynağı Hz. Ali’ye ve İmamı Gazali'ye dayandırılmaya çalış1ır. Sembollerin İbn-i Ömer ve Ali İbn-i Talip’ten nakledildiğini söyleyenler de bulunmaktadır (el-Hüseynî, Kenzu'l Esrar: 2005, 73; Budge: 2011, 89). Bu sembol dizisine ilk defa Hz. Ali tarafından yazıldığı iddia edilen Celcelutiye isimli bir kasidede ve Hz. Ali'nin divanında yer verildiği iddia edilmektedir (Graham, A Comparison: (t.y.), 4-6). Ancak farkl1 şekillerde Celcelutiye kasideleri bulunmakla birlikte söz konusu mühürden veya sembollerden, onların fonksiyonundan bahseden herhangi bir ifade görülmemektedir. Celcelutiye azimetini okumadan evvel yerine getirilmesi gereken tam da mühürdeki sembollerin sayısı kadar 7 usul/adap bulunmaktadır. Buna göre okumaya mesut bir saatte ve tam bir taharetle başlamak gerekir. Sonrasında niyet etmek, okumadan önce en az bir gün oruç tutmak, 66 defa Lafza-i Celal'i okumak, huşu ile kıbleye karşı iki diz üzerine oturmak, noksansız okumak, yavaş yavaş ve doğru okumak ve sonunda 3 defa salat ve selam getirmek gerektiği söylenir (el-İstanbulî: 2005, 194; el-Hüseynî, Kenzu'l Esrar: 2005, 193 94).

Bazılarına göre Allah, havas ilmini Kuran'1 gönderdiği gibi Cebrail aracılığıyla bir kitap olarak Hz. Muhammed'e göndermiştir. Onun tarafindan bilinen bu ilmi daha sonra Hz. Ali'ye aktardığına ve Hz. Ali'nin de kendisinden sonra gelen imamlara vasiyet ettiğine, imamların da bu bilgileri halka haber verdiklerine inanılmıştır. İmamlar indirilen bu kitap yoluyla olmuş veya olacak olayları öğrenmiştir. Hatta Hz. Ali'nin torunlarının, dünyanın sonuna dek gelecek bütün dinleri ve olacak siyasi olayları önceden bildikleri ve bu bilgileri bir kitapta topladıkları ifade edilmektedir. Onlara göre zamanla da bu kitaptaki bilgiler birer simge olarak görülmüş ve çeşitli yorumlar yapılmıştır (Uluğ: 2017, 159). Gerçeklerden uzak bu yorumlar özellikle Hz. Ali'ye dayandırılmaya çalışılmıştır. Sembolün Hz. Ali’ye nispet edilmesinden dolayı, mühür hem Sünni sufi okulları hem de Şia İslam'ı tarafından benimsenmiştir. Şia mistikleri, Hz. Ali tarafından keşfedildiğine olan inançları gereği bu mühre özel bir önem vermişlerdir. Mührün en erken görüldüğü tarih olarak, Fatimi İsmaili çalışması olan Risalat el İsm'el Azam'a bağlayanların olduğu söylenir. Ayrıca mühür Babiliğin öncülerinin ve Şeyh, Bahai gibi hareketlerin de ilgisini çekmiştir. Mühürde yıldızın 
kullanılmaya başlandığı dönemin Fatimi İsmaili hazinelerinin birleştirildiği zaman olmasının ihtimalinden de bahsedilir ki bu dönemdeki mühür dizisi en eski Yahudi serisine daha yakındır (Graham, A Comparison: (t.y.), 3-5).

Bazı rivayetlere göre ise $\mathrm{Hz}$. Ali bu mührü bir taşın üzerinde resmedilmiş halde bulmuş, bunu insanlara Allah'ın en büyük ismi, İsm-i Azam olarak tanıtmıştır. Yine, Hz. Ali'ye atfedilen Celcelutiye kitaplarında Hz. Ali'nin 'Muhakkak ki bu İsm-i Azam yeşil ipek üzerine yazılmış olarak semadan indirilmiştir' dediği şeklindeki ifadeye yer verilmiştir (İmâm Gazâlî, Celcelutiye: 2011, 8285). Mührün, İsm-i Azam olduğuna dair ve İsm-i Azam'la ilgili literatürde pek çok hikâye anlatılmasına rağmen anlatılanların kaynağı ve İsm-i Azam'ın hangi isimden veya isimler grubundan oluştuğu bilinmemektedir.

Mührün karşımıza çıktığı bir başka yer ise Ahmed er-Rufai grubudur. Müritler mührü beyaz çuha üzerine siyah ibrişimle işleyip başlarına gül mührülRufai gülü olarak takmışlardır. Her ne kadar Ahmed Rufai'den gelen bir gül mührü olmadığı söylense de Sadiyye ve Bedeviyye dervişleri bereket amacıyla işledikleri bu şekilleri gül olarak başlarında taşımışlardır. Gül mühürlerinin aslen Kadiriyye tarikatından geldiği de iddia edilmektedir. Kadiriye tarikatının halkalı kemerinde de yedi sembolün bulunduğu söylenilir. Aşağıda bir örneğini verdiğimiz gül mührünün dışında çok faklı gül mühürleri bulunmaktadir.

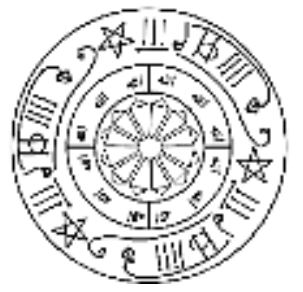

Şekil 12 Gül mühürlerinden bir örnek, (el-İstanbulî: 2005, 147,194-208).

Mühürdeki sembollerin tamamının kullanılmasının dışında altı uçlu yıldızın tek başına yer aldığı örneklerin sayısı oldukça fazladır. Yıldız sembolü Memluk ve Altınordu Devleti parasında ve ilkel hali de Sümer mühür kabartmalarında görülebilmektedir (Bilgili: 2014, 66). Yine beş köşeli ve altı köşeli yıldız sembollerini Osmanlı tılsımlı gömleklerinde görmek mümkündür. Buna Şehzade Cem Sultan'ın tılsımlı gömleği örnek verilebilir. Selçuklu dönemi örneklerinde ise Mührü Süleymanlı yüzükler, Türkmen parası ve gümüş kolyeler (Tezcan: 2011, 47-131), şifa tasları (Bilgili: 2014, 66) bulunmaktadır. Bunların dışında İslam ve Yahudi gelenekleri literatüründe altı köşeli yıldız için yapılan çok farklı yorumlara da ulaşılmakta ve genellikle altı köşeli yıldızın koruyucu güçle donatıldığına inanılmaktadır (Gibson: 2013, 103). Kuzey Afrika'da da altı köşeli yıldız, ruhları uzaklaştırmada önemli bir rol oynar ve duvarlar, kapılar ve muskalarda yer alır. Arap halk edebiyatında ise Hz. Süleyman'ın verimlilik büyüsü yaptığı, üzerinde mühür bulunan bir yüzüğü Mısır kralının elçisine verdiği söylenir. Ayrıca, Süleyman mührü üzerinde "Allah'ın en büyük isminin" yazılı olduğuna ve ona büyük bir güç verdiğine inanılır (Zbinden: 1994, 31,152). Fakat Kur'an'da böyle bir mühürden bahsedilmez. Kur'an, Allah'ın Hz. Süleyman'a bir nimet olarak cinler ve şeytanlar gibi gözle görünmeyen varlıkları emrine verdiğini söyler (Altuntaş: 2018, 58).

Havas bilgilerinin İslami kültüre tam olarak nasıl girdiği bilinmese de İslam alimleri tarafından çoğunlukla bir havas kitabı olan Şemsü'l-Maarif isimli kitabın yazarı olan Ahmet elBuni'nin havas bilgilerine ulaşmak için Hermetik birikimin yaygın olduğu bilinen Mısır'a seyahat ettiği ve Yunanlıların bu işlerle ilgili kitaplarından ve antik dönemin okült ilimlere dair kitaplarından ve Keldani kültüründen aynı zamanda Yahudi Kabala öğretilerinden de faydalandığı ve İbrani ve Süryani kültürlerini de karıştırarak kendi kitabını yazdığı ve İslami bir şekil vererek İslam toplumuna 
sunduğu düşünülmektedir (Witkam: 2007, 183-185; Graham, A Comparison: (t.y.), 5; Ceyhan: 2010, 532). Kitap'ta bu kültürlerin izleri rahatlıkla görülebilmektedir.

Havas alimlerine göre mühür ve büyü formülü değişirse o büyü tutmaz. Değişerek geldiği görülen mührün, büyü prensibine göre etki etmemesi gerekmektedir. Bir havas kitabında kitabın yazar1 "... bir misal ile verdiğim tılsım şekilleri en küçük bir dikkatsizlik ve hata sebebiyle tamamıyla manası değişeceği gibi kıymetini de tesirini de kaybeder. Bu sebeple bu tılstmlardan fayda ve tesir ummak herhalde kar-ü akıl olmasa gerek." demekte ve değişen tılsımın işlemeyeceğini söylemektedir (İloğlu: (t.y.), 996). Büyücülerin her hâlükârda tuttuğunu iddia ettikleri bu sembollerin esasen değişmesi büyü mantığına göre tılsımı etkisiz hale getirmektedir.

\section{Sonuç}

Semboller girdiği kültürlere göre şekle bürünmüss ve mührün bazı sembollerinde farkl11ıklar oluşmuştur. Havas bilgilerinin İslami kültüre giriş şekli tam olarak bilinmese de bir havas kitabı olan Şemsü'l Maarif isimli kitabın yazarı Ahmed el-Buni tarafindan XIII. yüzyıllarda Müslümanlara tanıtıldığı iddia edilebilir. Mühürleri, İslami geleneğin bir ürünü olarak görmek isteyenler bu sembollerin Allah tarafından vahiy olarak indirildiğine ve Hz. Ali'ye verildiğine inanmak istemişlerdir. Mührün kaynağını Hz. Ali'ye dayandırma gayreti içinde olan Şii ve Sünni gruplar mühre sahip çıkarak onu yüceltmişler ve mührün yaygın olarak kullanılmasında etkili olmuşlardır. Günümüzde de Hz. Ali'ye nispet edilmesinden dolayı Şia İslam'ı tarafından ön plana çıkartılmıştır. Bununla birlikte, mühürler Selçuklu ve Osmanlı dönemlerinde de kullanılmıștır. Mührün karşımıza çıktığ 1 bir başka yer ise Ahmed er-Rufai grubudur. Fakat gül mührü denilen yedi sembollü mührün esasen Rufai grubundan değil, Kadiriyye tarikatından geldiği de iddia edilmektedir.

Kendi içinde anlamlı bir bütünlüğü olmadığı görülen yedi sembollü mühürlerin şifresini çözebilmek amacıyla her sembole farklı harfler atanmıştır. Bu sembollerin Allah'ın esmalarını temsil ettiği söylenmiş, yedi sembole yedi gün, yedi cin kralı, yedi melek, yedi gezegen ve bazen de renkler ve madenler tahsis edilmiş ve bunlarla büyüsel cedveller hazırlanmıştır. Bunun yanında koruyucu ve büyüsel özelliklerinin olduğuna inanılan vefklerde ve tılsımlarda da bu sembollere yer verilmiştir. Ayrıca mühürler görünmez varlıklarla, cinlerle iletişime geçmenin yolları olarak görülmüş her sembolün bir melek ve hadiminin/cininin olduğu düşünülmüştür. İnsanlar tarafindan bu sembollerin bir taraftan Allah'ın en büyük esmasına işaret ettiğine, diğer taraftan da cinlerle irtibat kurmaya yarayan şifreler olduğuna inanılmıştır.

Büyüsel uygulamalarda kullanılan bu sembollerin verilen örneklerden de yola çıkarak değişerek günümüze kadar geldiği açık bir şekilde görülmektedir. Değişerek gelen yedi sembolle oluşturulan formüllerin büyü prensibine göre etki etmemesi gerekmektedir. Çünkü bunlar bir bakıma reçetedir; değişirse büyü formüllerine ve büyücünün amacına uygun olmaz; çünkü formül bozulur. Şifreleme sisteminin mantığına uygun olan da bir metnin her halükârda işe yaraması değil; ancak uygun şartlar sağlandığ 1 zaman tek bir şekilde veya bir kimse için etkili olmasını sağlamaktır. Şifreleme işlemleri sınırlamak amacıyla yapılmasına rağmen havas kitaplarındaki bu tılsımlı semboller asırlardır sınırsız işler için kullanılmış hatta akıl almaz özellikler ve dinsel bir anlam yüklenilerek istismar aracı olarak kullanılmıştır. Şu bir gerçek ki büyü, dini unsurlardan koparsa ayakta kalamaz.

\section{KAYNAKÇA}

Abdu'l-Fettâh es-Seyyid el-Tûhi, Kitâbu Sihru'l-Kehhân fi Huduri'l-Cân, Mektebetu'l-Sekafiyye, Beyrut (t.y). 
Abdurrahman Altuntaş, “Kur'an'da Hz. Süleyman'a Verilen Nimetler', Turkish Studies, Comparative Religious Studies, Volume 13/17, Summer 2018.

Ahmed bin Ali el-Bûnî, “el-Lü'lü vel-Mercân fî Teshîri Mülûki'l-Cân, Mektebetu's-Sekafiyye, (y.y) (t.y).

Ahmed Hüseyin Remal b. Mevlevî, Kenzu'l-Hüseyni ve Kehlu'l-Ayn, Nüshatu'l-Muterceme, (y.y) (t.y).

Alexander Fodor, A Group of Iraqi Arm Amulets, Popular Islam In Mesopotamia, Quaderni di Studi Arabi, Vol. 5/6, Gli Arabi nella Storia: Tanti Popoli una Sola Civiltà (1987-1988), pp. 259277.

Alî b. Ebî Tâlib b. Abd el-Mattalib el-Hâşimi, el-Kasidetü'l-Celcelutiye, (y.y.) (t.y.), Milli Kütüphane Yazmalar Koleksiyonu, 06 Mil Yz A 3400/2.

Alparslan Salt, Ansiklopedi Neo-Spiritüalist Yaklaşımlarla Ezoterik Bilgilerin Işığında Semboller, Ruh ve Madde Yayınları, İstanbul 2006.

Arif Pamuk, Berhetiyye Havas ve Esrarl, Pamuk Yayınları, İstanbul (t.y).

Arthur Edward Waite, The Book of the Ceremonial Magic, Global Grey, London 2013.

Aryeh Kaplan, Sefer Yetzirah, The Book of Creation, Samuel Weiser, York Beach Maine (t.y).

Arzu Evecen \& Mustafa Gürbüz Beydiz, "Paleolitik ve Neolitik Dönem Bulgularında Giyim Kültürü”, Turkish Studies, Social Science, Volume 13/10, Spring 2018.

Birgül Bozkurt, "Harf Gizemi ve Sembolizmi Bağlamında İhvan-1 Safa'da Hurufiliğin İmkanı", Turkish Studies, Comparative Religious Studies, Volume 13/2, Winter 2018.

Bülent Kısa, Büyü Notlarl, (y.y), (t.y).

Bülent Kısa, Havass' in Derinlikleri, Hermes Yayınları, İstanbul 2005, I. Kitap.

Clare Gibson, Semboller Nasıl Okunur, Resimli Sembol Okuma Rehberi, Yem Yayınları, İstanbul 2013.

Desmond Morris, Koruyucu Tılsımlar, Uğurlar, Muskalar, Nazarlıklar, Çev: Mehmet Harmanc1, İnk1lap Yayınları, İstanbul 1999.

E.A. Wallis Budge, Amulets and Magic, Routledge Taylor\&Francis Grouo, London and New York 2011.

Ebu Mesleme el-Mucrîtî el-Endelûsî, Gâyetu'l-Hakîm, Mektebetü İşaatül İslam, Hindistan, H.343.

el-Hâc Abdu'l-Fettâh es-Seyyid Abduh el-Tuhi, Kitabu Mürşidi'l-İnsan ila Ruyeti'l-Can, Mektebetu's-Sekafiyye, Beyrut 2003.

Emilie Savage Smith, Magic and Divination in Early Islam, Ashgate Variorum, UK 2004.

Emilie Savage Smith, Magic and Divination in the Medieval Islamic Middle East, Blackwell, History Compass, (2011), s.s. 622-233.

Ernst Zbinden, İslâm'da ve Eski Ortadoğuda Cin ve Ruh İnançları (İslâm), Ter: Ekrem Sarıkçığlu, Yeni Ufuklar Neşriyat, Samsun 1994.

Gershom Scholem, Magen David, Encyclopedia Judaica, c. XI, Kater Publishing House, Jerusalem (t.y).

Gershom Scholem, The Curious History of the Six-Pointed Star, (у.у.) 1949. 
H. Stanley Redgrove, Bygone Beliefs, Being a Series of Excursions in the Byways of Thought, Paternoster Row, E.c.4, London 1920.

Helmut Werner, Ezoterik Sözlük, Çev: Bülent Atatanır, v.d., Omega Yayınları, İstanbul 2005.

Hülya Tezcan, Topkapı Sarayı Müzesi Koleksiyonundan Tılsımlı Gömlekler, Timaş Yayınları, İstanbul 2011.

İbnu'l-Hâc el-Tilmisanî'l-Mağribî, Şumusu'l-Envar ve Künuzu'l-Esrâri'l Kubrâ, Daru'l-Ceyl, Beyrut H.737, c.I-II.

İmam Ahmed bin Ali el-Buni, Şemsü'l-Maârif (Büyük Bilgiler Güneşi), Ter: Selahattin Alpay, Sedef Yayınevi, İstanbul 1979, 243, c.I .

İmam Ahmed el-Buni, Şemsü'l-Maarifil Kübra, Mektebetü'l Sakafiyye, Beyrut/Lübnan, ty., 89, c.I.

İmâm Gazâlî, Celcelutiye Manevi Zırh, Ter: Halil Günaydın, Pamuk Yayıncılık, İstanbul 2011.

İmâm Gazâlî, el-Afâk, Murada Giden Yol, Dualar, Tilsımlar, Büyüler ve Çözümleri, Çev: H.Mustafa Varlı, Esma Yayınları, İstanbul 1999.

Jan Just Witkam, "Gazing at the Sun Remarks on the Egyptian Magician al-Būnī and his Work", Arabic Studies on Science and Literary Culture, Edited by: Arnoud Vrolijk\&Jan P. Hogendijk, Brill, Leiden. Boston 2007, 183-200.

J. MoG. Dawkins, The Seal of Solomon, The Journal of the Royal Asiatic Society of Great Britain and Ireland, No. 2 (Oct.,1944), pp. 145-150.

Kamile Ünlüsoy, Tarihi Şahsiyeti ve Anadolu İnanç Kültüründeki Tasavvurlarıyla Hz. Ali, XIIIXVI. Yüzyıllar, Basılmamış Doktora Tezi, Isparta 2011.

Lloyd D. Graham, A Comparison of the Seven Seals in Islamic Esotericism and Jewish Kabbalah, (y.y.) (t.y.).

Lloyd D. Graham, Quranic Spelling: Disconnected LetterSeries in Islamic Talismans, Artick L.D.Graham, (y.y) 2011.

Mecmû'atü'l-Ed'îye ve'l-Havâs, (t.y.), Milli Kütüphane, 29-36, 06 Mil Yz A 4028.

Mehmed b. Ali Ezinevi, Risâle-i Esrâr-ı Hurûf, H.121816), Milli Kütüphane Yazmalar Koleksiyonu, Ankara, 52, 06 Mil Yz A 169/1.

Muhammed b. Muhammed b. Muhammed b. Mesudu'l-Zelyetenî, Kitâbu Mâhi'l-İnkâr ve Hâdiye'lHayrân ile'l-Ulumu'l-Acibeti'l-Garibe, (y.y) (t.y.).

Muhammed er-Rıza er-Radavî, et-Tuhfetu'r-Radaviyye fi Mücerrebâti'l-İmâmiyye, Muessesetu Ehli'l-Beyt, Umman (t.y.).

Muhammed Sâmî Muhammed Ahmed, el-Karîn ve'r-Riyâdiyyât er-Ruhâniyye, Daru'l-Fikr ve'sSekafe, (y.y) (t.y.).

Mustafa Ertuğrul, Dua Hazinesi, Kenzül Dua-I Fethiyye fi Esrar-ül Hurufiyye, Sağlam Yayınevi, İstanbul (t.y.).

Mustafa İloğlu, Havas Gizli İlimler Hazinesi, Seda Yayınları, İstanbul (t.y.), 8. Kitap, 1799.

Nimet Elif Uluğ, Osmanlı'da Batıl İtikatlar ve Büyü, Doğan Kitap, İstanbul 2017.

Nimet Yı1dırım, Fars Mitolojisi Sözlüğü, Kabalcı Yayınları, İstanbul 2008.

Nuray Bilgili, Türklerin Kozmik Sembolleri Tamgalar, Hermes Yayınları, İstanbul 2014. 
Saadettin Merdin, Vahiy Ürünü Kaside-i Celcelutiye ve Hz. Ali'nin Said Nursi’yi Çağlar Öncesinden Haber Vermesi: 6 Kasim 2018, http://www.saadettinmerdin.com/genel/275-vahiy-urunukaside-i-celcelutiye-ve-hz-alinin-said-nursiyi-caglar-oncesinden-haber-vermesi.html\#_ftn2.

Sedat Veyis Örnek, Sivas ve Çevresinde Hayatın Çeşitli Safhalarıyla İlgili Batıl İnançların ve Büyüsel İslemlerin Etnolojik Tetkiki, Ankara Üniversitesi Basımevi, Ankara 1966.

Semih Ceyhan, Şemsü'l-Maarif, TDV İslam Ansiklopedisi, İstanbul 2010, c.38.

Seyyid Muhammed Takî'l-Mukaddem, Hizanetu'l-Esrar el-Hutumu ve'l-Ezkar, Tercüme ve Tahkik: Musa Kasîri'l-Âmili, Müessesetu'l-A'lemî li'l-Matbuat, Beyrut 2001, c.I.

Seyyid Muhyiddîn İbnu'l-Arabi, el-Kibritu'l-Ahmâr ve Sirru'l-Efkâr ve Daru'l-Cevher, (у.у.) H.636.

Seyyîd Süleymân el-Hüseynî, Kenzu'l Esrar Fi'l Havas ve'l Ezkar, Türkçeleştiren: H. Mustafa Varlı, Esma Yayınları, İstanbul 2005.

Seyyid Süleyman el-Hüseynî, Kenzü'l-Havâs ve Keyfiyet-i Celb ve Teshir, Cemiyet Kütüphanesi, İstanbul 1332, c.IV.

Şerif-i Şems, Vekâyi 'i Felek-i Has, Daru'l-Maarif el-İlâhiyye, H.1393.

Şeyh Ahmed Diyrûbî, Kitabu Fethu'l-Mülk, (Fethu'l-Mülkü'l-Mecîd el Müellefu li-nefi'l-Abid), Misir H.1187.

Şeyh Ahmed Diyrûbî, Mucerrebati'l-Diyrûbî el-Kebîr (Fethu'l-Mülkü'l-Mecîd el Müellefu li-nefi'lAbid), Mektebetu'l-Ticâriyyeti'l-Kubra, Misır, 1123.

Şeyh er-Ruhani eş-Şeyh Atiye, Havassu'l-Kur'an, (y.y) (t.y).

Şeyh Samur Hindî, Risâle-i Samur Hindî, (y.y), (t.y.).

Şeyhu'r-Ruhânî Fahruddîn Tâhir Câbir Halevî, Kahiru'l-Ervâh, (y.y.), (t.y.).

Menbeu Usulul-Hikme, (y.y) (t.y), c.IV.

Şinasi Gündüz, “T11sım”, Din ve İnanç Sözlü̈̆̈̈, Vadi Yayınları, Ankara 1998.

Yahya Agah b. Salih el-İstanbulî, Tarikat Klyafetlerinde Sembolizm, Ocak Yayınc1lık, İstanbul 2005.

Yusuf Çakar, Gizli İimler, Yedirenk, İstanbul 2005.

Zeki Kuşoğlu, Tılsımdan Takıya, Pimapen Kültürevi, İstanbul 1998.

\section{EK:}

\begin{tabular}{|c|c|c|c|c|c|c|c|}
\hline (II) & & & 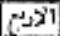 & 872 & $y$ & & \\
\hline$\approx$ & $\dot{3} \rightarrow$ & 20 & $\cos$ & $\dot{\phi \theta} \theta$ & 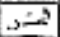 & & \\
\hline & & 10 & $\omega$ & 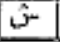 & $\tau$ & 3 & \\
\hline 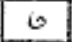 & 2 & $1+11$ & 年 & 5 & $\sqrt{11}$ & ts & \\
\hline 5 & ה ب- & ي & $=$ & تك & & 21 & \\
\hline
\end{tabular}

Şekil 13 Beş satırdan oluşmuş bir cetvel türü (elTûhi, Kitâbu Sihru'l-Kehhân (t.y).

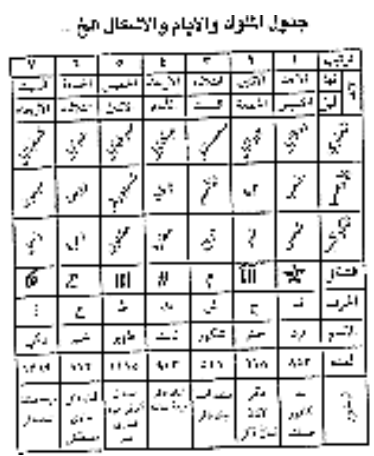

Şekil 14 On bir satırdan oluşan bir cetvel örneği, (el-Tûhi: 2003, s.131). 


\begin{tabular}{|c|c|c|c|c|c|c|}
\hline 6 & iil & 5 & \# & IIII & 6 & 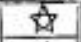 \\
\hline$j$ & $\dot{t}$ & 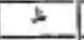 & $\dot{3}$ & $\dot{v}$ & E. & ن \\
\hline (3) & 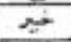 & طي & $\div 5$ & تسكري & بار & قر \\
\hline كنيبيز & هنبابيل & تربييل & بك & $\overline{J i k}$ & بمائل & 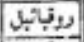 \\
\hline 0 & \pm 1 & $\mid \dot{s} ; \nabla^{2}$ & $35 x$ & Ti & $\therefore$ & ain \\
\hline $4^{4}$ & $2+1$ & |lit & الإزباء & $x \times \pi$ & الآنبين & $t \rightarrow 31$ \\
\hline ز زه & $i \infty j$ & sit & ع بمار & سيب & تسر & Rn \\
\hline
\end{tabular}

Şekil 15 İyilik ve sevap için oluşturulmuş bir cetvel (Halevi: (t.y), Sayfa Yok; el-Tilmisanî'lMağribî: H.737, 72)

\begin{tabular}{|c|c|c|c|c|c|c|c|c|}
\hline$\frac{5}{5}$ & 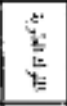 & है & $\frac{3}{5}$ & 5 & 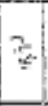 & ه & 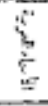 & $E$ \\
\hline - & ردتَّميا. & | ملهب & 8 & ضسى & | & الشبتيلي & زغد & \\
\hline & : & & $\pi$ & تمر & 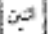 & 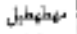 & ماد & \\
\hline صتدل المر & $=$ & |S-5بر & t & مر & | & تهيطبل & ثكيد & ث \\
\hline ري. & مبكاتيز | & برتلن & \# & صطرد & |ربا. & نهنبلبل & نابت & \\
\hline & مرزباتلال & "ئهردن: & IIII & ثHت & |خبسر & تمبهot & خلخير & \\
\hline ترئنل & غيانيل & نوبيد & e & iرj & $+\infty$ & =هافطبل & خجب & \\
\hline s. & كسباتيا. & ميرن & 6 & زئر & مبتر & - خبعلبلي & ركت & \\
\hline
\end{tabular}

Şekil 16 Yedi satırla oluşturulmuş bir cetvel türü, (Usulul-Hikme, (t.y), 254).

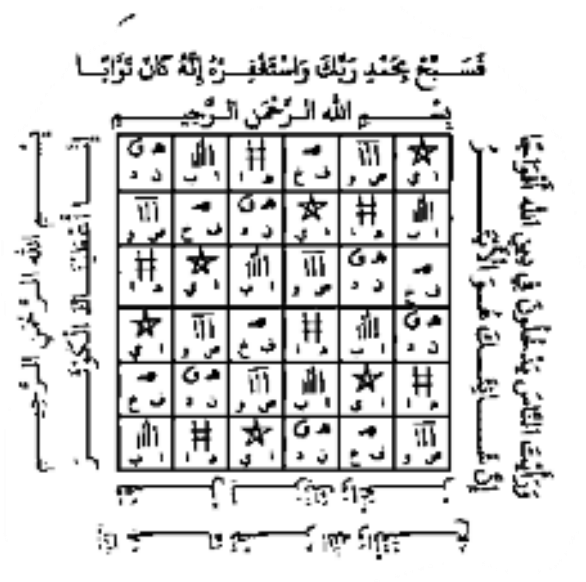

Şekil 17 Farsça bir kitaptan alınmış 6x6'lı vefk, (Şerif-i Şems: H.1393, 57).

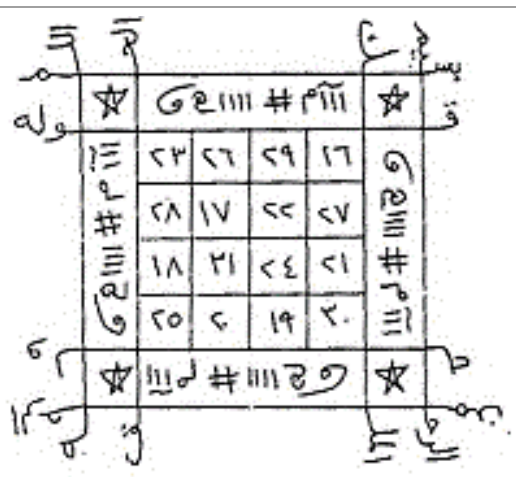

Şekil 18 Yedi sembollü mühür ve $4 \times 4$ lü vefkin birleşmesiyle oluşturulmuş bir tılsım, (UsululHikme, (t.y), 254).

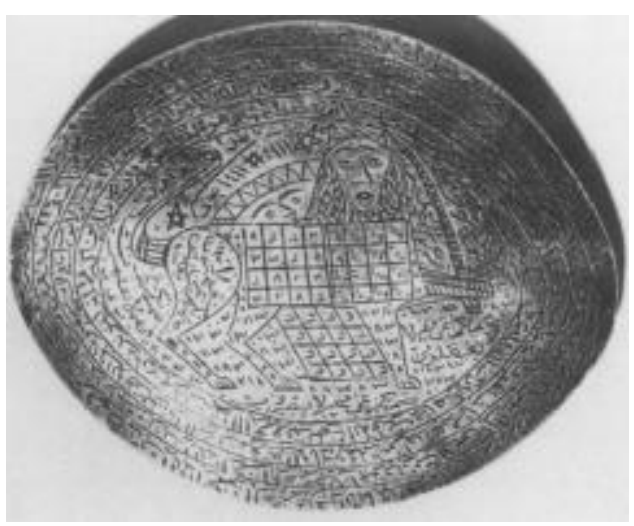

Şekil 19 Yedi sembolün şifa tasında kullanımına bir örnek, (Fodor: (1987-1988), 273).

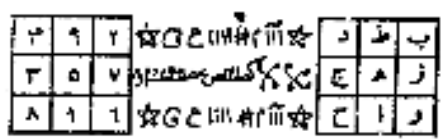

Şekil 20 İşlere etki etmesini sağlamak için vefk ve mühürle hazırlanmış bir örnek, (Usulul-Hikme, (t.y), 182). 


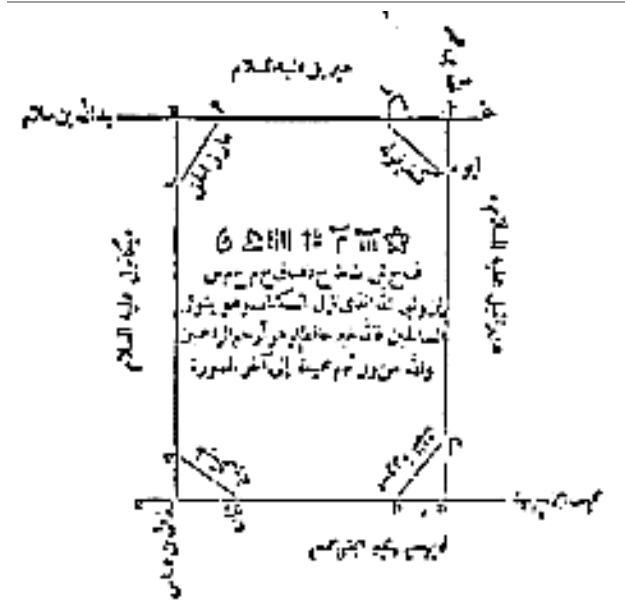

Şekil 21 Faydasının sayılamayacak kadar çok olduğu söylenilen bir tılsım, (el-Tilmisanî'lMağribî: H.737, 102).

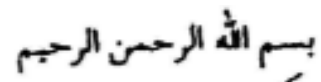 \\ rererer⿳亠口冋口巾 $\leadsto 6$ eIIIH hill}

Şekil 22 Hastaya şifa için 7 gün boyunca suya konularak hastaya içirilmesi tavsiye edilen bir tılsım, (el-Hüseynî, Kenzu'l Esrar: 2005, 331)

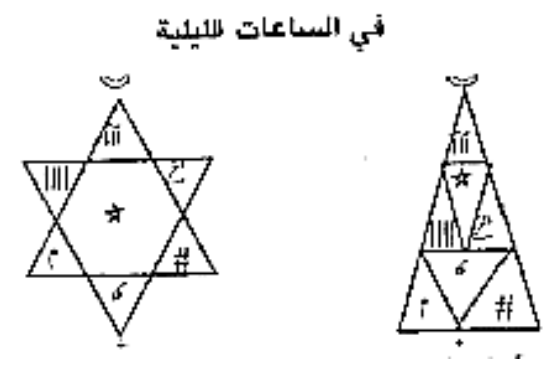

Şekil 23 Gece kullanılması için hazırlanmış tılsım, (el-Tûhi: 2003, s.133).

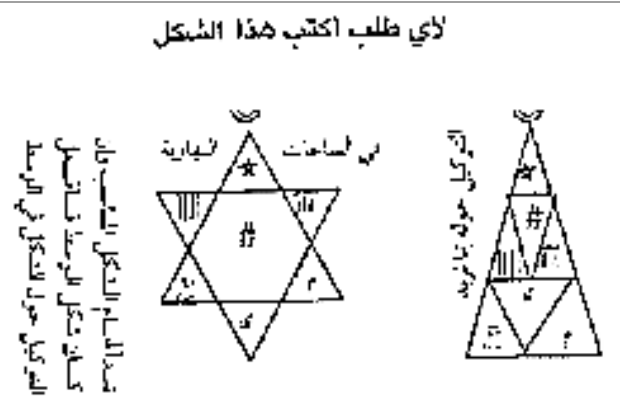

Şekil 24 Gündüz kullanılması için hazırlanmış bir tılsım, (el-Tûhi: 2003, s.1). 